\title{
On the Construction of Practical Teaching System with the Aim of Improving Students' Ability
}

\author{
Dong Liu \\ Institute of Information Science and Technology South China Business College Guangdong \\ University of Foreign Studies, Guangdong, Guangzhou 510545, China.
}

78972493@163.com

Keywords: Practical teaching; curriculum system; innovative ability; ability enhancement.

\begin{abstract}
The goal of talent cultivation in colleges and universities is closely related to the construction of practical teaching system. As a strong technical application major, the key to achieve the goal of teaching is to improve students' practical ability. This paper explores the construction of a scientific practical teaching system from the aspects of strengthening the concept of practical teaching, setting up practical courses and training professional skills. On the basis of students' mastery of theoretical knowledge, it can promote the improvement of students' abilities in an all-round way through the combination of theoretical basis and practical teaching, in-class teaching and extracurricular practice, practical teaching and scientific research training.
\end{abstract}

\section{Introduction}

How to build an educational system to adapt to the development of innovative education and cultivate innovative talents has become an important mission of colleges and universities [1]. In order to raise the level of talent training and enhance students' social adaptability and competitiveness, we must closely follow the needs of society, reform the curriculum, teaching content and methods, and adopt an open and scientific teaching plan. Flexible and effective teaching methods to ensure the completion of teaching tasks and the realization of training goals. Only when we attach importance to, strengthen and improve the practice teaching links, reform the content and mechanism of practice teaching, construct a practical teaching system suitable for cultivating innovative talents, and develop and perfect continuously, can we serve the society. Will cultivate a strong sense of career and social responsibility, innovative spirit and practical ability of high-quality talent.

\section{The Importance of Practical Teaching}

Classroom teaching is the main form of basic teaching of professional theory in colleges and universities, but there has always been a phenomenon of emphasizing theory and neglecting practice, which makes practical teaching relatively weak in the cultivation of talents in colleges and universities. It is not enough to train compound engineering talents only by classroom theory teaching, but practice teaching is also needed. Computer related major is an applied subject. On the one hand, it is necessary to strengthen the cultivation of students' hands-on operation ability, on the other hand, teachers should discuss and study with students in practical teaching, and cultivate students' ability to think and solve practical IT project problems. Practical teaching is the main link to realize the goal of talent training, and it is also a mutual support with theoretical teaching. The unity of support is the key to practice theory, verification of theory and development theory, and plays an important role in improving students' comprehensive quality and cultivating innovative spirit and practical ability. [2]

However, the teaching work is faced with the problems of how to construct the practical curriculum system, optimize the content of practical teaching and improve the students' practical ability. To strengthen the importance of practical teaching, it is necessary to reform the current credit system. The core problem is what kind of optional courses can be offered to students. The curriculum design determines the direction and goal of training, and it is directly related to the construction of students' knowledge system and the cultivation of their abilities. Therefore, we should change the 
traditional teaching concept and make the professional training plan based on the social development and demand.

\section{Constructing a Scientific and Rational Course System of Practical Teaching}

The construction of practice teaching system should aim at improving students' innovation ability, practice ability and comprehensive quality. The practice teaching system is a complete and orderly organic whole. It is a process of practice teaching arranged according to the professional training goal and the progress of theoretical teaching. The construction of practice teaching system should meet the actual needs of most people, according to the students' different learning foundation, characteristics and interests, as much as possible to set up personalized practical curriculum modules, build an open platform for practical innovation. To give students as many opportunities to learn and practice, to give students more distinct and more personal professional ability and quality connotation. From the actual situation of this major in our school From the point of view of the experience of other colleges and universities, we must arrange practical courses every semester, link up practical courses with theoretical teaching, increase the proportion of practical courses, and adopt progressive courses from easy to difficult. "Develop students' practical ability step by step" [3].

\subsection{Highlight the Application Link in the Teaching Content.}

While emphasizing the system theory construction, pays attention to the operational training content. In curriculum design, it not only strengthens students' understanding of curriculum theory knowledge, but also promotes students' practical ability. The form of in-class practice teaching is diversified, and the main form is project teaching. Through the analysis of real enterprise project cases, the students' grasp and application of theoretical knowledge are strengthened, and their thinking and thinking ability of problem solving are cultivated. In the project teaching, the selected cases closely revolve around the teaching content and are close to the students' learning practice, so that the students become active in learning time varying passively.

\subsection{Combination of Professional Skills and Innovation and Entrepreneurship.}

Skilled technical skill is the foundation and source of innovation and entrepreneurship, and the basic expectation of society to specialized talents. The ultimate goal of learning practice is employment, which is to create more value for society and human beings. Therefore, in the construction of practical teaching system, we should fully consider the employment needs of students, consider the practical problems that students may encounter in their entrepreneurship, and take the practical content of students' first position as the focus of daily practical training. The whole process of practice teaching runs through innovation and entrepreneurship.

\subsection{Combination of Intra-class Teaching and Extracurricular Practice.}

Extracurricular practice is an important way to cultivate students' practical ability, innovation ability and improve students' comprehensive quality. It is an important part of practical teaching and a beneficial supplement to the practice in class [4]. Through the students' scientific and technological innovation activities, rich and colorful community activities and social practice activities, this paper verifies the theoretical knowledge, strengthens the practical innovation ability, and cultivates the students' social cognition, social adaptation and social competition ability.

\subsection{Combination of Practical Teaching and Scientific Research Innovation.}

The advantages of scientific research in colleges and universities should be brought into full play and the methods and new achievements of scientific research should be transformed into practical teaching in time so that students can understand the most advanced academic trends and science and technology. At the same time, it is necessary to practice the students' solid experimental technology, master solid theoretical knowledge, and reserve conditions and bases for scientific research and innovation. [5]. 


\section{Practical Teaching Setup to Improve Students' Ability}

The practice teaching form of information science and Technology College has been enriched and perfected gradually from single to comprehensive, from isolation to system. Professional practical teaching includes in-class experiments, course design, training week, professional practice, graduation practice and graduation design.

\subsection{Experimental Teaching of Specialized Courses.}

The traditional experimental teaching is basically completed in the school laboratory. All the professional courses are arranged in the experiment, such as the "program design foundation" course has the verifying experiment, the "electronic circuit technology" course has the design experiment, the "database principle and the application" course has the comprehensive plan experiment, and the software engineering course has the actual project. The experimental teaching of professional courses is combined with virtual network, and cloud platform is constantly improving.

\subsection{Comprehensive Practical Teaching.}

Not every course has a comprehensive practice section. It was originally arranged at the beginning of the next semester after the end of the class. After adjusting the current "programming basis", "Electronic Circuit Technology", "Database principles and applications", these three professional courses have arranged a comprehensive course practice. In the course of teaching, the students are informed of the contents of the comprehensive practice in advance, and the tasks are arranged into the end of the semester, and the students are trained two weeks after the teaching week in the second to fourth semester. The simultaneous promotion of the teaching content and the comprehensive practical content not only plays a role in reviewing and consolidating knowledge, but also because of the immediate use of learning, students encounter The problem can be solved at that time, which is very helpful to improve the learning efficiency of professional class and the students' ability to solve problems.

\subsection{Professional Practical Teaching.}

Starting from the fifth semester, professional practice teaching is performed by the engineer of the signed practice base company. At this stage, the basic courses of computer major have been learned, and the intervention of enterprise engineers, relying on the actual IT projects of the enterprise, can embed the operation of the enterprise and the latest professional technology into the practice teaching. At the same time, professional practice will also lay the foundation for the upcoming elective courses. Through professional practice teaching, students have a comprehensive understanding of professional development and important knowledge points and overall tasks.

\subsection{Graduation Practice and Graduation Design.}

At the beginning of the seventh semester, our school instructs teachers to report graduation design topics, which are all in line with the students' training projects. Each student can choose a topic or take the form of self-made topics to enter the graduation design stage. A 4-week graduation internship is arranged at the start of the eighth semester. Students can take independent practice or centralized practice, internship guidance teachers through alumni state tracking students practice.

To organize students to participate in the training of national computer software and proficiency examinations, to encourage students to participate in this examination, to obtain the qualification of intermediate engineers, and to become composite talents with diplomas, degree certificates and professional qualifications, Enhanced the student's employment ability and the work adaption ability.

\section{Summary}

At present, in the case of a large number of compressing professional credits, the proportion of professional courses is decreasing constantly. Some contents of professional courses are embedded in practical teaching. Some contents related to actual projects are transferred to practical teaching, which can adapt to the requirements of current teaching reform.

In the teaching link, through strengthening and perfecting the experiment teaching course, the practice teaching base and the construction of the scientific research innovation platform, the 
students' basic innovation ability, comprehensive innovation ability and independent innovation ability are constantly enriched and promoted. It emphasizes the comprehensive development of students' knowledge, ability and quality, the mastery of basic knowledge and basic skills, the cultivation of innovative spirit and practical ability, and keeps pace with the times in practice. In practice teaching, new attempts and reforms are constantly carried out, and new contents are injected, which is the way of development of practice teaching.

\section{Acknowledgments}

Department of education of Guangdong province 2016 featured innovation projects (education and research development), "Research on training model of applied talents of computer major based on curriculum group and ability oriented training", project number: 2016GXJK224

2016 South China Business College Guangdong University of Foreign Studies Project quality engineering practice teaching base in Hangzhou turtle Technology Co. Ltd. teaching base.

\section{References}

[1]. Ni Honiara. Exploration of practical Teaching Reform of Automation undergraduate Specialty [J] .Journal of Hangzhou University of Electronic Science and Technology: social Science Edition: No.2009, 5(1):73-75.

[2]. Yao Xiangfei, Xu Penguin. Practical Exploration of cultivating innovative talents in Engineering in Teaching and Research Universities: reform and Construction of College practice Teaching system based on the Promotion of students' innovative ability [J] .Journal of Changchun University of Technology2010, 5(7):1-2.

[3]. Chen Zhao, Zhang Bing. An attempt at the Reform of the New Credit system for Advertising Specialty [J]. China's out-of-school education,2010(9):92.

[4]. Zeng Yongwei, Liu Goring. An Analysis of the Scientific Construction of practical Teaching system under the background of "Excellence Plan" [J] .Chinese University Teaching: 2011, (7):75-78.

[5]. Tan HI, Cao Honey, Lu Yuma. Reform of practical Teaching system and cultivation of innovative ability [J] .higher Architectural Education: 2011, 20(1):116-118. 